Supporting Information

\title{
Elucidating the Extraordinary Rate and Cycling Performance of Phenanthrenequinone in Aluminum Complex-Ion Batteries
}

Dong-Joo Yoo and Jang Wook Choi*

School of Chemical and Biological Engineering and Institute of Chemical Processes, Seoul

National University, 1 Gwanak-ro, Gwanak-gu, Seoul 08826, Republic of Korea

AUTHOR INFORMATION

Corresponding Author

*E-mail: jangwookchoi@ snu.ac.kr 


\section{Experimental Methods}

Synthesis of Materials: 9,10-phenanthrenequinone (PQ,>99\%), 1-butyl-1-methylpyrrolidinium bis(trifluoromethylsulfonyl)imide (Pyr14TFSI, >99\%, <500 ppm $\mathrm{H}_{2} \mathrm{O}$ ), LiTFSI (99.5\%), 1ethyl-3-methylimidazolium chloride-aluminum chloride $\left((\mathrm{EMImCl})_{2}\left(\mathrm{AlCl}_{3}\right)_{3}\right)$ were purchased from Sigma-Aldrich. Activated carbon (AC0830) was purchased from Asahi Organic Chemicals. $1 \mathrm{M} \mathrm{LiPF} 6$ in EC/DEC was purchased from PANAX ETEC. All the materials were used without further purification. $\mathrm{AC}(\mathrm{PQ})$ was prepared based on the following procedure: $1 \mathrm{~g}$ of $\mathrm{AC}$ and $3 \mathrm{~g}$ of PQ were ground together in a mortar. The well-mixed composite was pelletized and heated at $250{ }^{\circ} \mathrm{C}$ for 3 hours in Ar atmosphere.

Cell Preparation and Electrochemical Measurements: The electrodes were prepared according to the following procedures. PQ or AC(PQ), super-P, and poly(vinylidene difluoride) (PVDF, Arkema) binder were uniformly dispersed in $N$-methyl 2-pyrrolidone in a weight ratio of 90:5:5. The well-mixed slurry was cast onto tantalum foil (99.95\%, Thermo Fisher) and spread by using the doctor blade technique. The cast electrodes were dried under vacuum at $80{ }^{\circ} \mathrm{C}$ for 24 hours, and the average loading of PQ alone was $1 \mathrm{mg} \mathrm{cm}^{-2}$. The mass content of PQ in AC(PQ) was evaluated using TGA, and the value was $48 \mathrm{wt} \%$. The electrochemical performance was characterized by preparing 2032 coin-type cells for LIBs or modified Swagelok-type cells for AIBs. The entire cell assembly process was carried out inside an argon-filled glove box. Cyclic voltammetry and galvanostatic measurements were performed using a battery cycler (WBCS3000L, Wonatech) at $25^{\circ} \mathrm{C}$. In the case of the AIB cells, galvanostatic measurements were carried out after $50 \mathrm{CV}$ cycles to activate the $\mathrm{AC}(\mathrm{PQ})$. The respective resistance values of the individual electrochemical processes were determined by using electrochemical impedance spectroscopy (VSP, Bio-Logic) in the frequency range of 0.01 to $10^{6} \mathrm{~Hz}$ in the temperature range $25-55^{\circ} \mathrm{C}$. 
Characterization: The morphologies of the $\mathrm{AC}, \mathrm{PQ}$, and $\mathrm{AC}(\mathrm{PQ})$ were characterized by using the field-emission scanning electron microscopy (SEM, JSM-7800F Prime, JEOL, Japan) and high-resolution transmission electron microscopy (TEM, JEM-3010, JEOL, Japan) instruments at the National Center for Inter-University Research Facilities (NCIRF) at Seoul National University. All the electrode samples subject to ex-situ characterizations were washed with 1,2dimethoxyethane, followed by drying under vacuum for $3 \mathrm{hrs}$. The functional groups of AC, PQ, and AC(PQ) were analyzed by Fourier-transform infrared spectroscopy (FTIR, JASCO FT/IR-6700). The X-ray diffraction profiles were obtained using an X-ray diffractometer (SmartLab, Rigaku) based on $\mathrm{Cu}-\mathrm{K} \alpha(\lambda=0.15406 \mathrm{~nm})$ radiation. The specific surface areas (SSAs) and pore size distributions were obtained from $\mathrm{N}_{2}$ adsorption-desorption measurements by using a porosity analyzer (Micromeritics, 3FLEX) operating at $87 \mathrm{~K}$. The chemical compositions were analyzed by XPS (Sigma Probe, thermo VG Scientific, England) with an $\mathrm{Mg} \mathrm{K} \alpha$ line as an X-ray source. ESR (EMXmicro, Bruker) analysis was performed at room temperature to detect the radical anion for the discharged $\mathrm{AC}(\mathrm{PQ})$.

DFT calculation: Geometrical optimizations and energy calculations were performed without symmetry restriction using the B3LYP hybrid density functional implemented in the GAUSSIAN 09 software package. ${ }^{1}$ The $6-31+\mathrm{G}(\mathrm{d}, \mathrm{p})$ basis sets were adopted for all the atoms. Frequency calculations at the same basis sets were performed to determine the nature of a stationary point as a true local minimum. For the potential calculations of PQ-1Li, PQ-2Li-1, PQ-2Li-2, and PQ-2Li-3, the polarization continuum model (PCM) with the ethanol parameter and dielectric constant $(\varepsilon=24.6)$ was used to implicitly take included solvent molecules into consideration. We calculated the potentials based on the following equation:

$$
E\left(v s . \mathrm{Li} / \mathrm{Li}^{+}\right)=\frac{\Delta G}{-n F}-1.4
$$


, where $E$ is the formal potential, $\Delta G$ is the free energy of reaction, $n$ is the number of electrons transferred in the reaction, and $F$ is Faraday's constant. The reference potential of $\mathrm{Li} / \mathrm{Li}^{+}$was determined by subtracting $1.4 \mathrm{~V}$ from the formal potential, because the SHE is $-4.4 \mathrm{~V}$ vs. vacuum and the potential of $\mathrm{Li} / \mathrm{Li}^{+}$is $-3.0 \mathrm{~V}$ vs. SHE. ${ }^{2}$ The desolvation energies were obtained by using the explicit solvation model in the gas phase to compare the trends between electrolytes. 

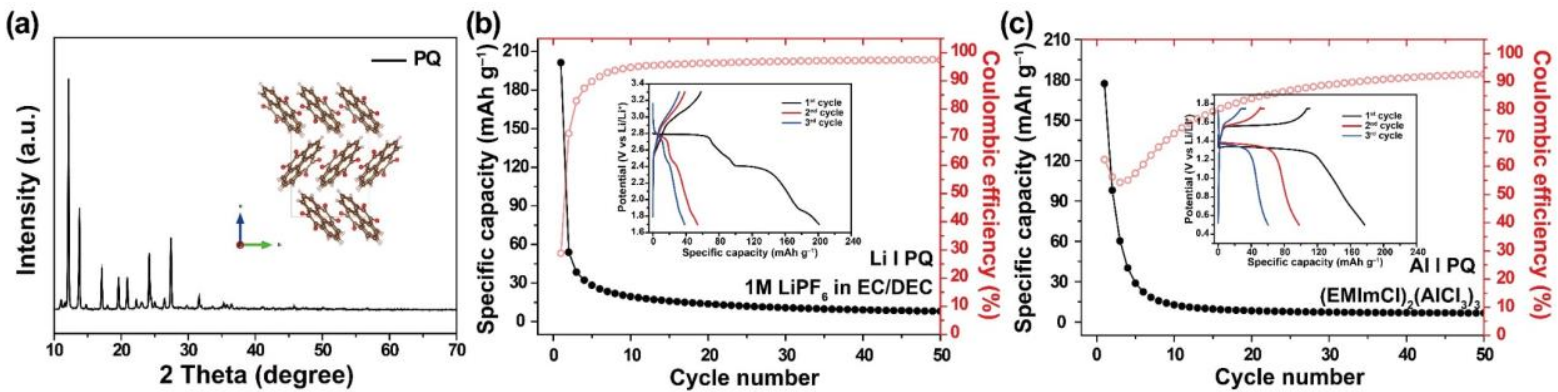

Figure S1. (a) XRD patterns of PQ. Cycling performance of PQ with (b) $1 \mathrm{M} \mathrm{LiPF} 6$ in EC/DEC and $(\mathrm{c})(\mathrm{EMImCl})_{2}\left(\mathrm{AlCl}_{3}\right)_{3}$ at a current density of $100 \mathrm{~mA} \mathrm{~g}^{-1}$, together with their voltage profiles (insets). 

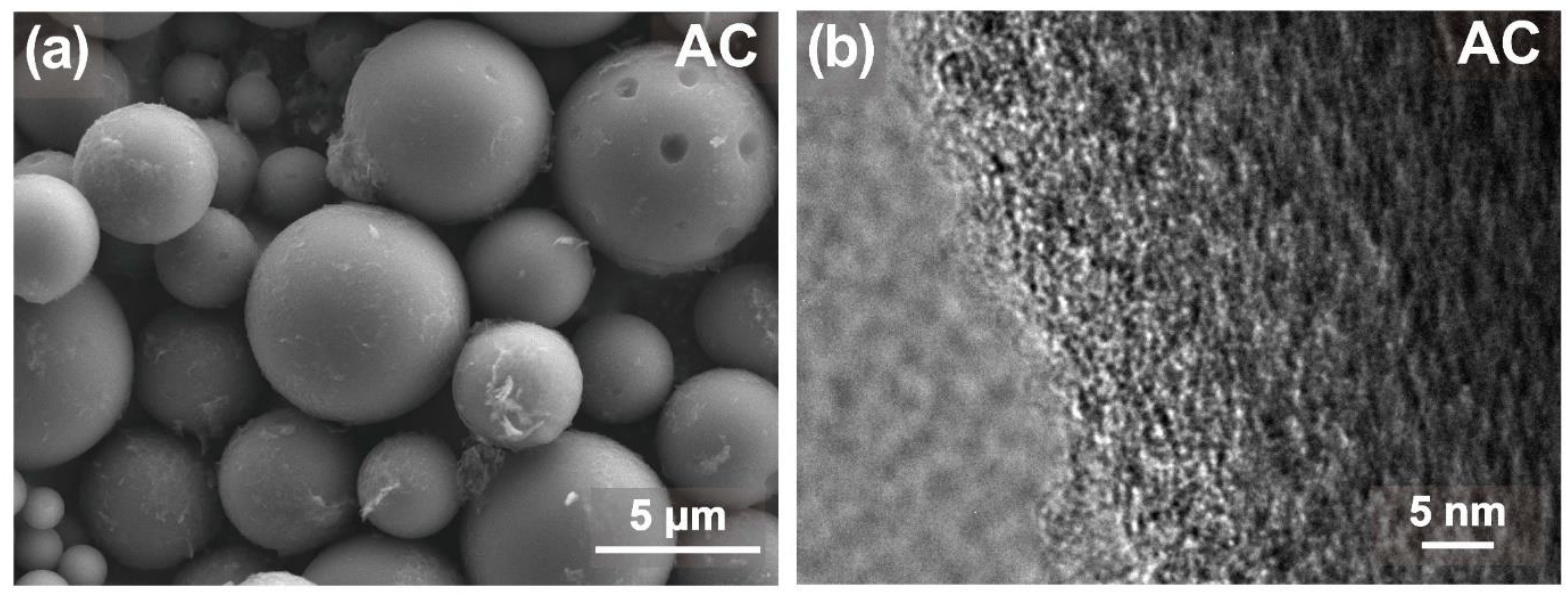

Figure S2. (a) SEM and (b) TEM images of AC. 

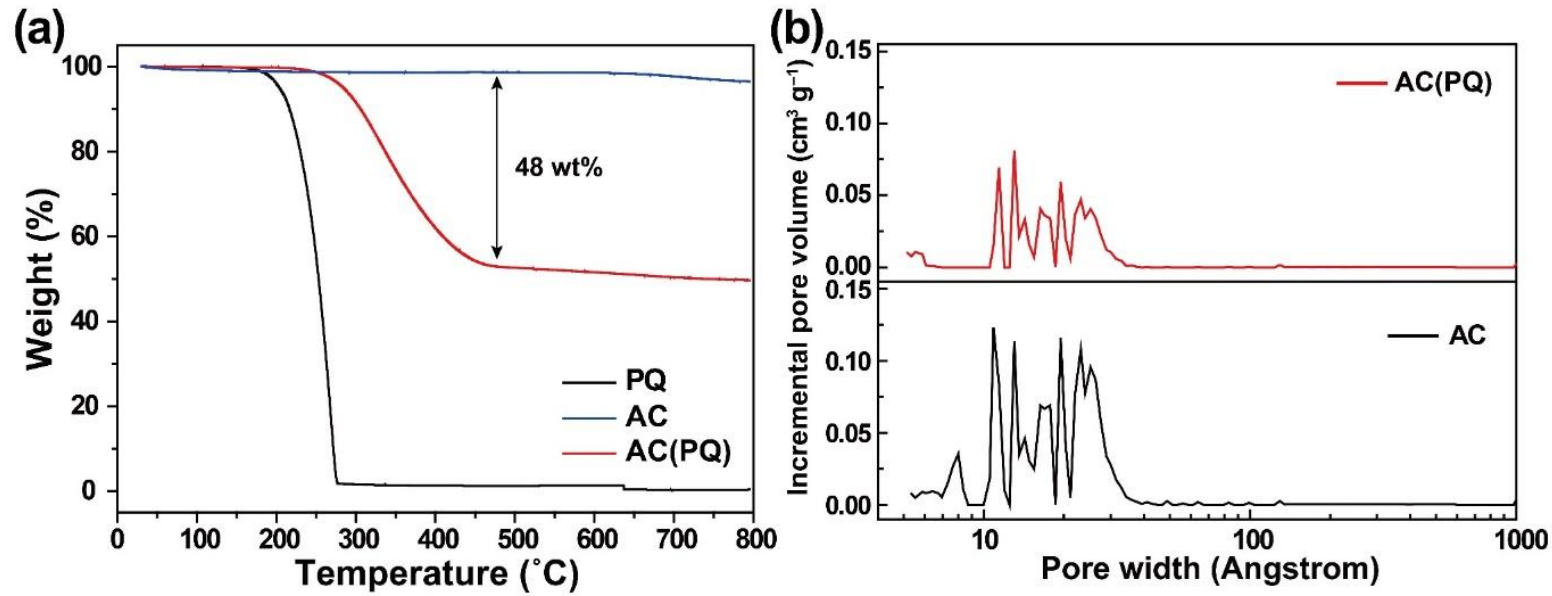

Figure S3. (a) TGA analyses of PQ, AC, and AC(PQ). (b) Pore width distribution curves of AC and $\mathrm{AC}(\mathrm{PQ})$. 

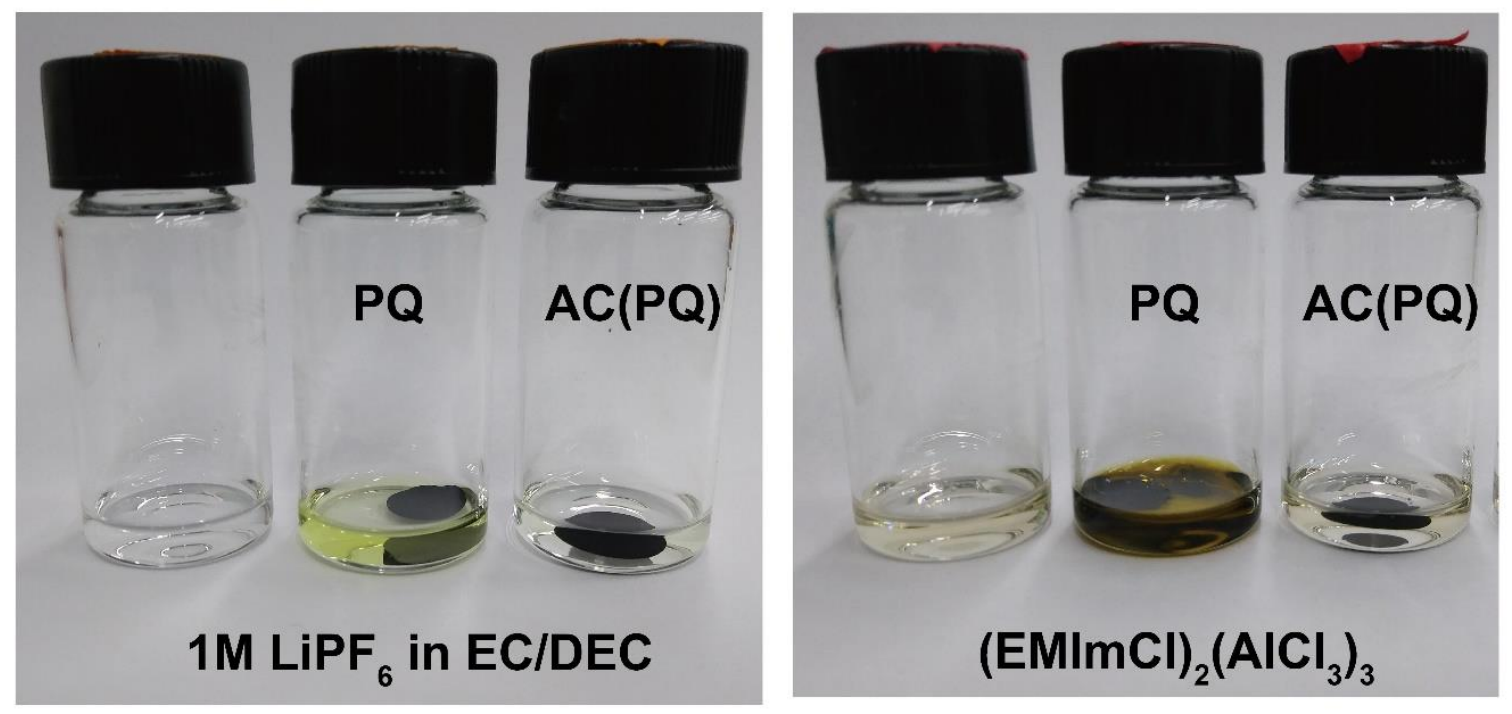

Figure S4. Digital photographic images of dissolution tests. PQ and AC(PQ) electrodes in $1 \mathrm{M}$ $\mathrm{LiPF}_{6}$ in $\mathrm{EC} / \mathrm{DEC}(\mathrm{left})$ and in $(\mathrm{EMImCl})_{2}\left(\mathrm{AlCl}_{3}\right)_{3}$ (right). 
(a)

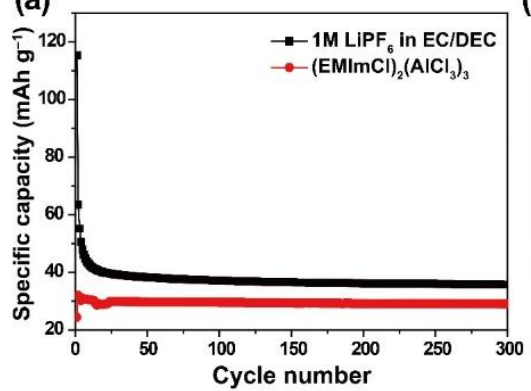

(b)

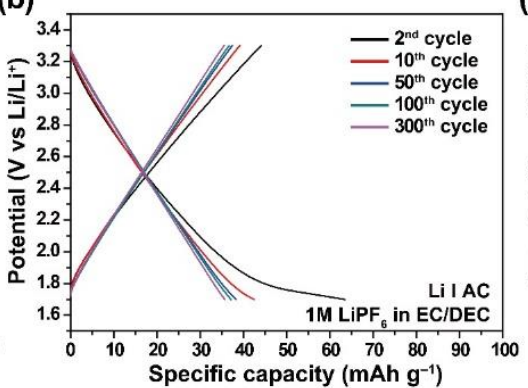

(c)

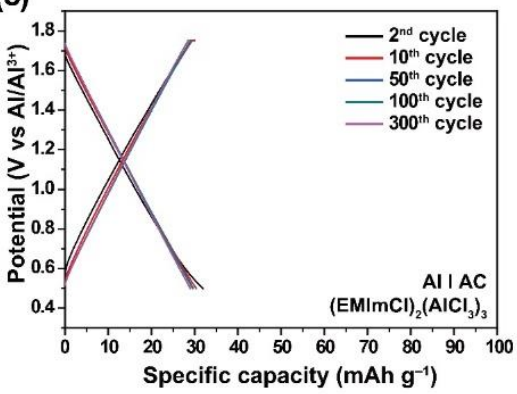

Figure S5. (a) Cycling performance of bare $\mathrm{AC}$ with $1 \mathrm{M} \mathrm{LiPF}_{6}$ in $\mathrm{EC} / \mathrm{DEC}$ and $(\mathrm{EMImCl})_{2}\left(\mathrm{AlCl}_{3}\right)_{3}$. Their voltage profiles after a different number of cycles with (b) $1 \mathrm{M} \mathrm{LiPF} 6$ in $\mathrm{EC} / \mathrm{DEC}$ and (c) $(\mathrm{EMImCl})_{2}\left(\mathrm{AlCl}_{3}\right)_{3}$. 


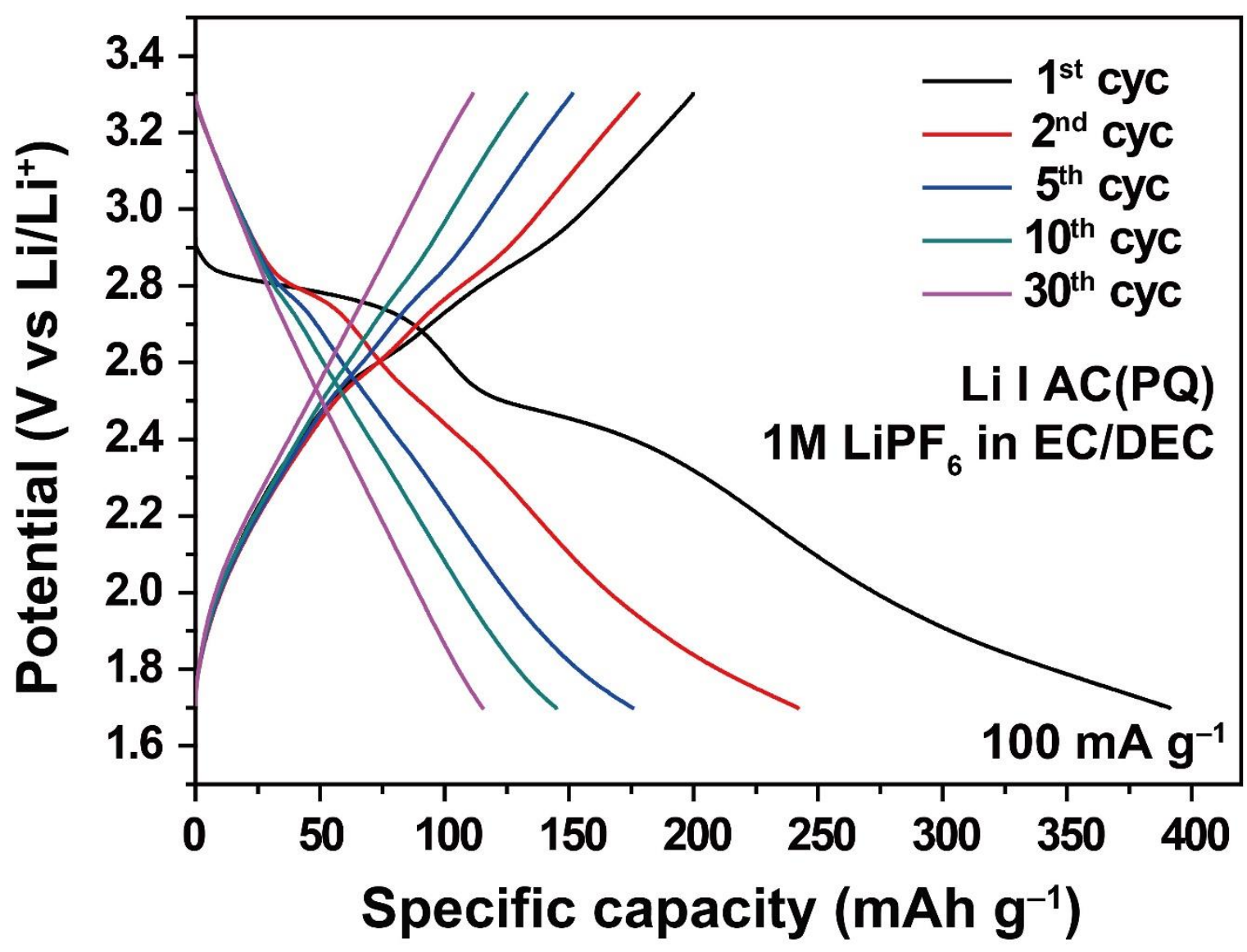

Figure S6. Voltage profiles after a different number of cycles in Figure $2 \mathrm{f}$. 


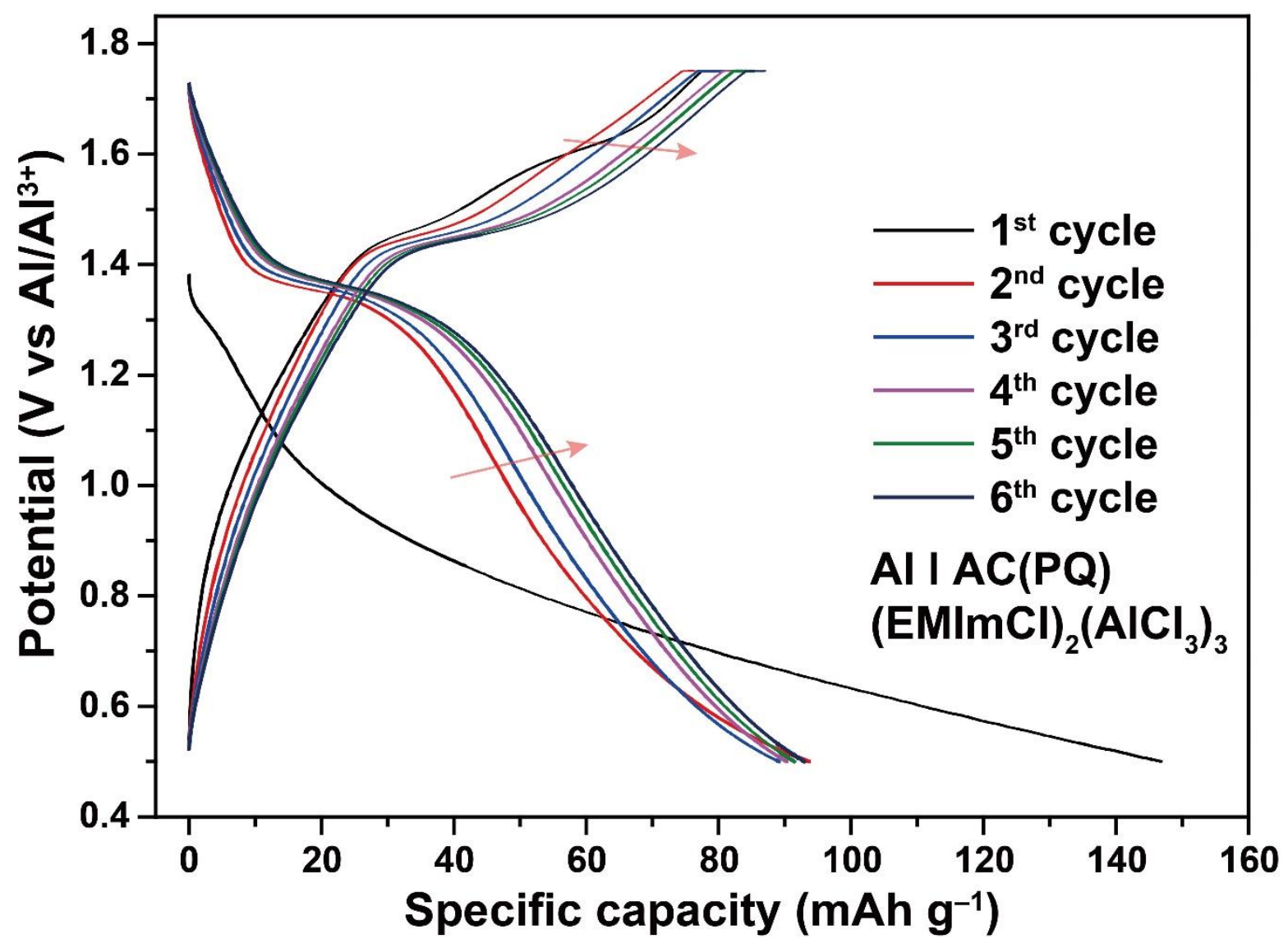

Figure S7. Voltage profiles of $\mathrm{AC}(\mathrm{PQ})$ with $(\mathrm{EMImCl})_{2}\left(\mathrm{AlCl}_{3}\right)_{3}$ at different cycle numbers without $\mathrm{CV}$ activation. 

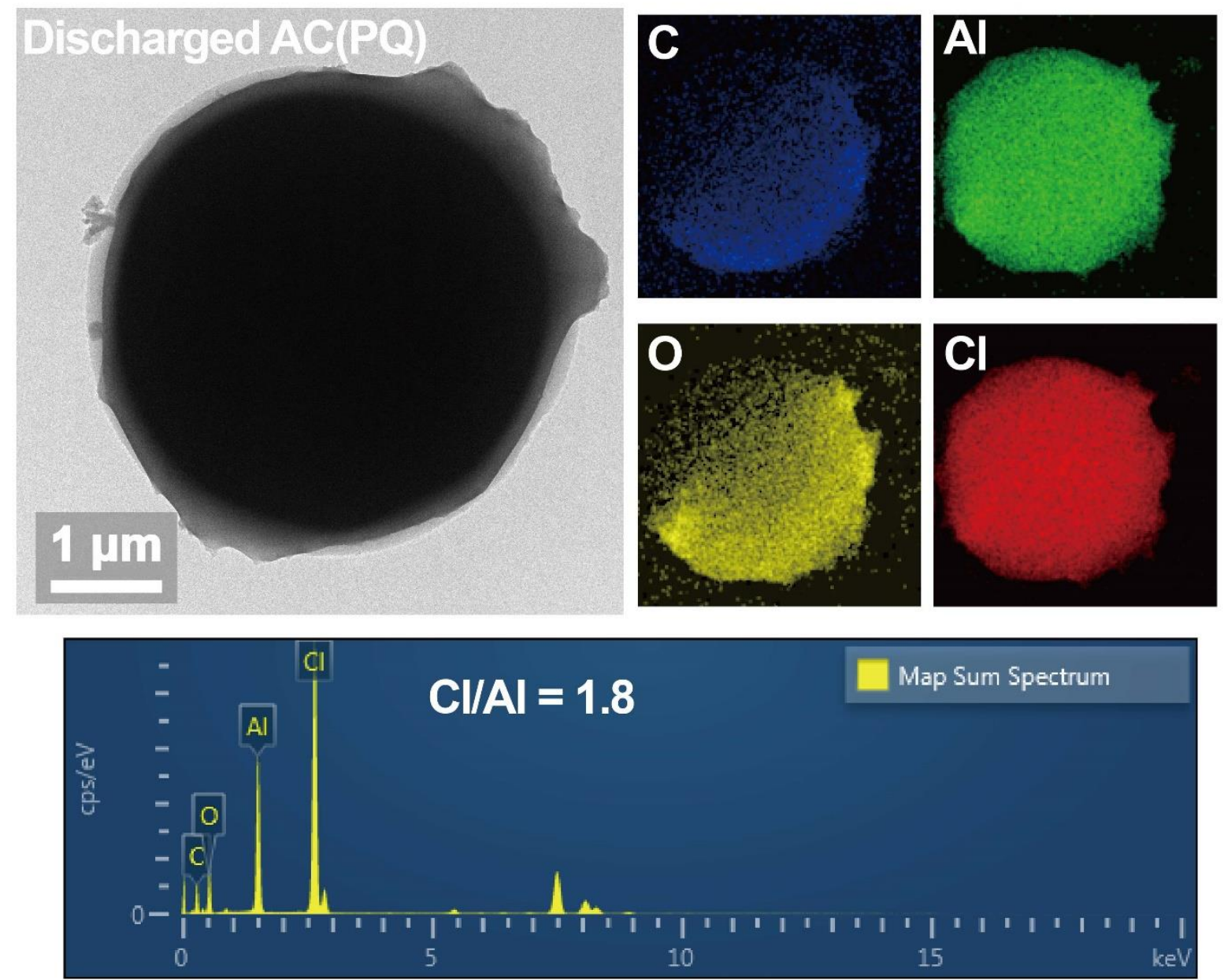

Figure S8. TEM image and EDS mapping of the discharged $\mathrm{AC}(\mathrm{PQ})$ with $(\mathrm{EMImCl})_{2}\left(\mathrm{AlCl}_{3}\right)_{3}$. 

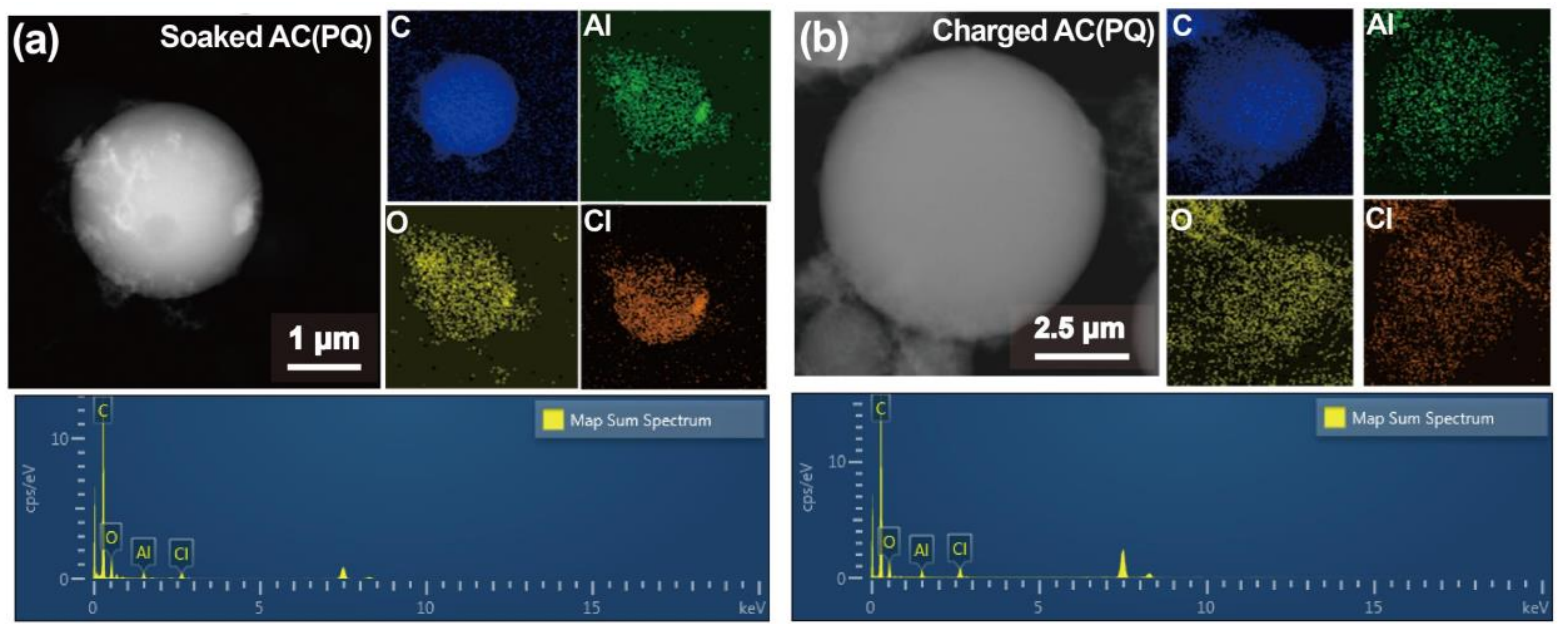

Figure S9. TEM images and EDS mapping of (a) soaked AC(PQ) and (b) charged AC(PQ) with $(\mathrm{EMImCl})_{2}\left(\mathrm{AlCl}_{3}\right)_{3}$. 

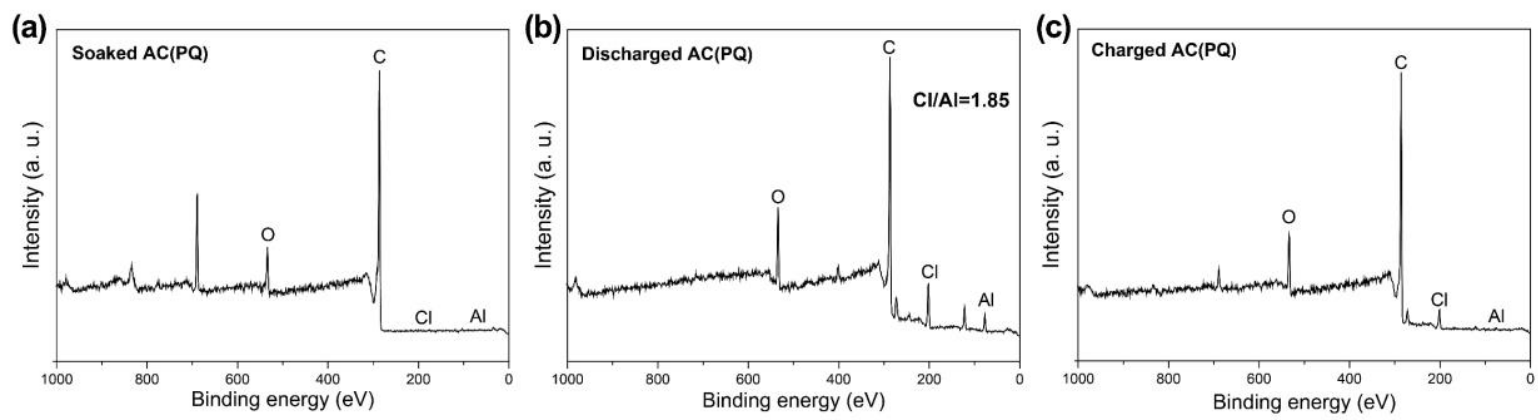

Figure S10. Full-range XPS spectra of the soaked, discharged, and charged AC(PQ) with $(\mathrm{EMImCl})_{2}\left(\mathrm{AlCl}_{3}\right)_{3}$. 


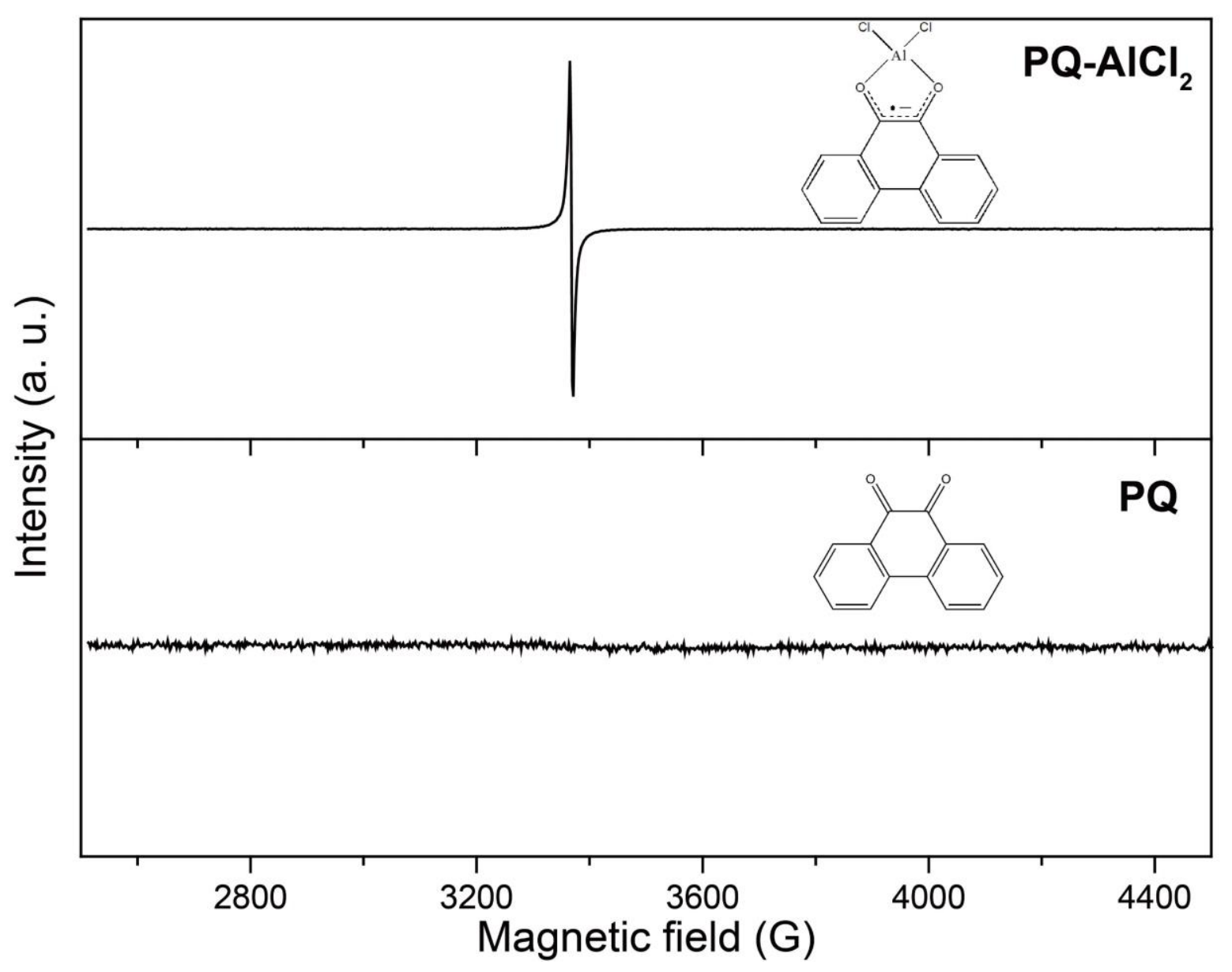

Figure S11. ESR spectra of the pristine and discharged $\mathrm{AC}(\mathrm{PQ})$ with $(\mathrm{EMImCl})_{2}\left(\mathrm{AlCl}_{3}\right)_{3}$. 

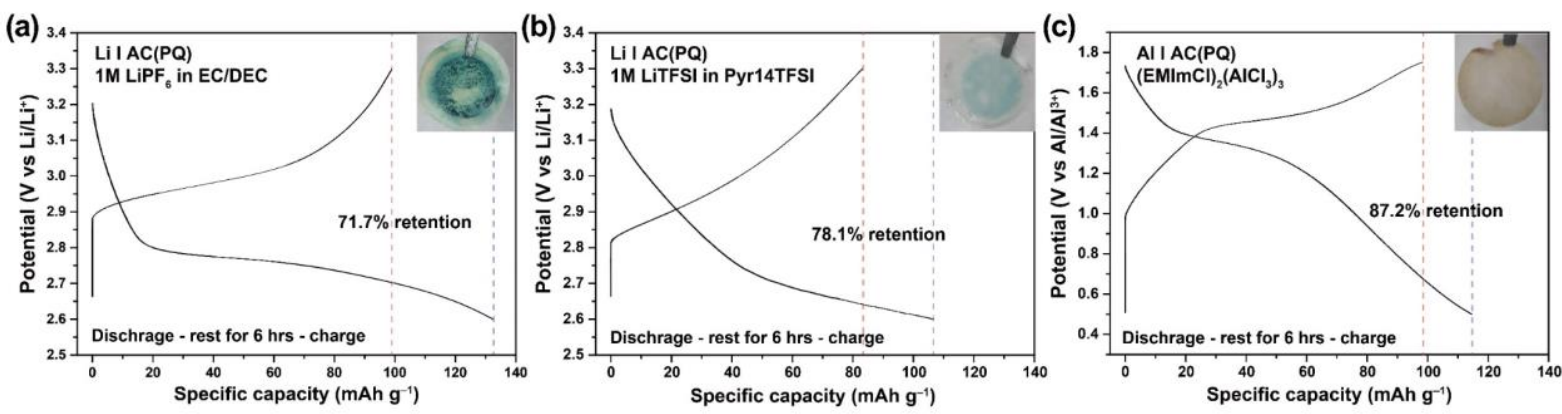

Figure S12. Voltage profiles of discharge and charge after $6 \mathrm{hrs}$ of rest at the discharged state:

(a) $1 \mathrm{M} \mathrm{LiPF}_{6}$ in EC/DEC, (b) $1 \mathrm{M}$ LiTFSI in Pyr14TFSI, and (c) (EMImCl)2(AlCl3)3. (Insets)

Photographs of the separators after the dissolution test. 

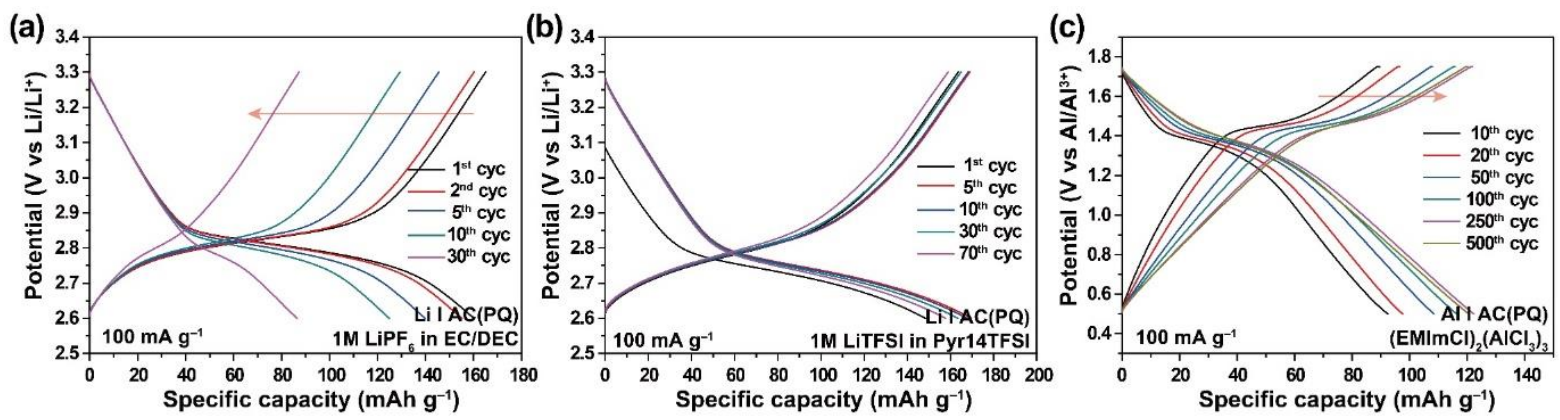

Figure S13. Voltage profiles at different cycles of AC(PQ) with (a) $1 \mathrm{M} \mathrm{LiPF} 6$ in EC/DEC, (b)

1M LiTFSI in Pyr14TFSI, and (c) $(\mathrm{EMImCl})_{2}\left(\mathrm{AlCl}_{3}\right)_{3}$. 

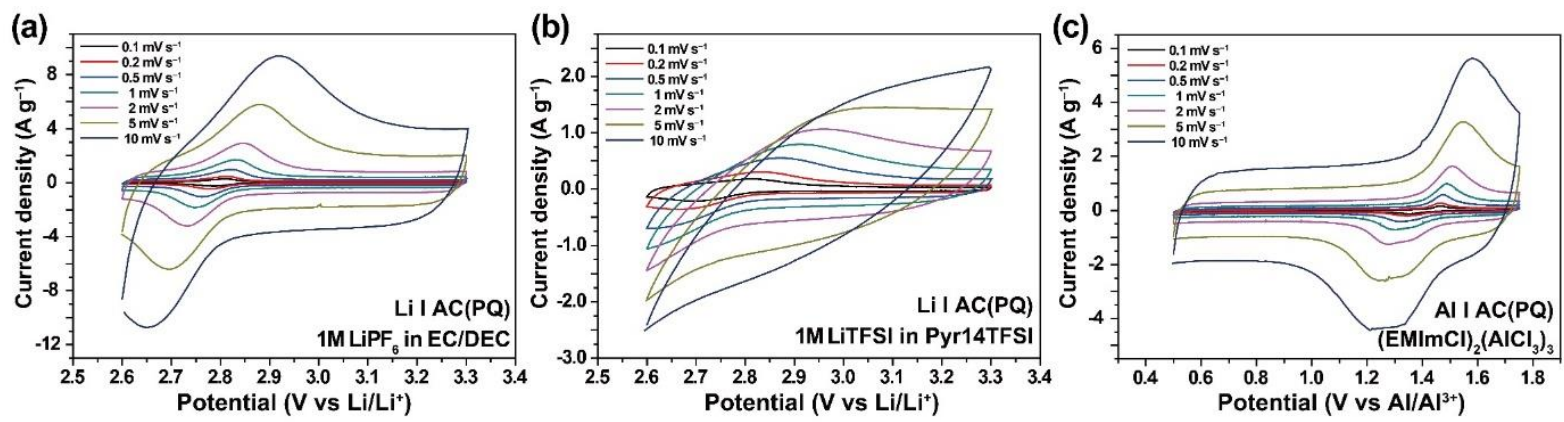

Figure S14. CV profiles of AC(PQ) at different scan rates with (a) $1 \mathrm{M} \mathrm{LiPF} 6$ in EC/DEC, (b) $1 \mathrm{M}$ LiTFSI in Pyr14TFSI, and (c) $(\mathrm{EMImCl})_{2}\left(\mathrm{AlCl}_{3}\right)_{3}$. 


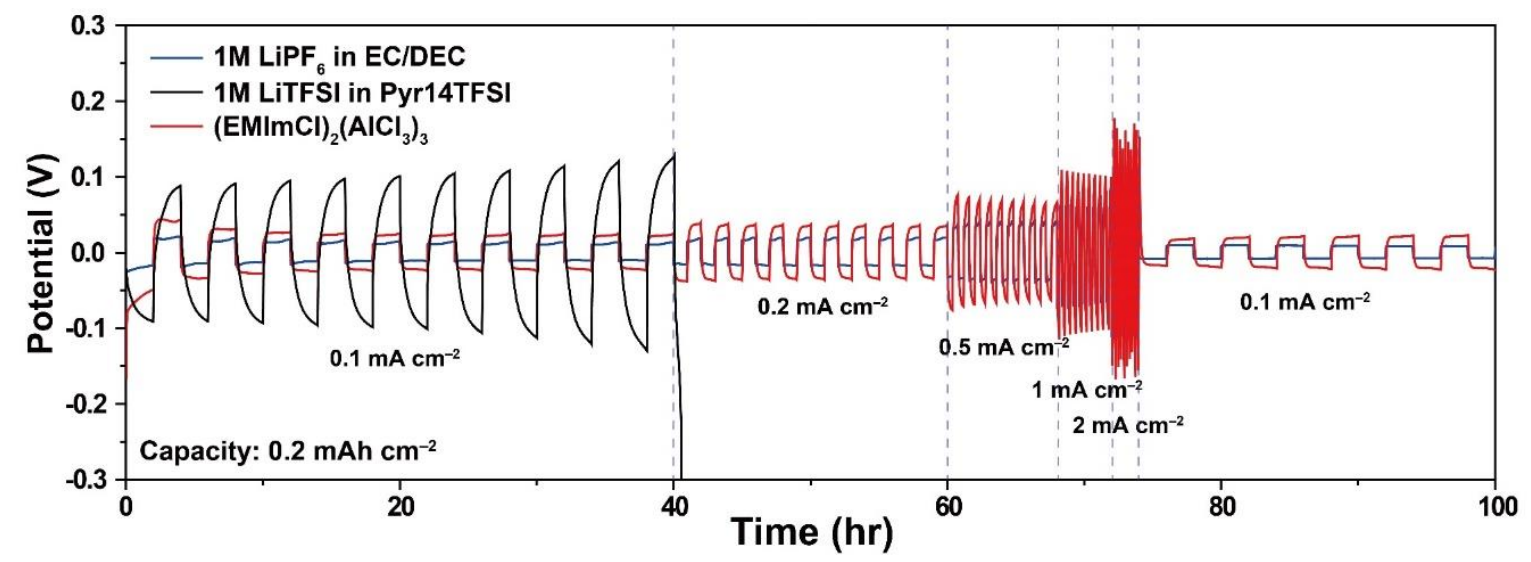

Figure S15. Voltage profiles of symmetric cells with different electrolytes at various current densities. 

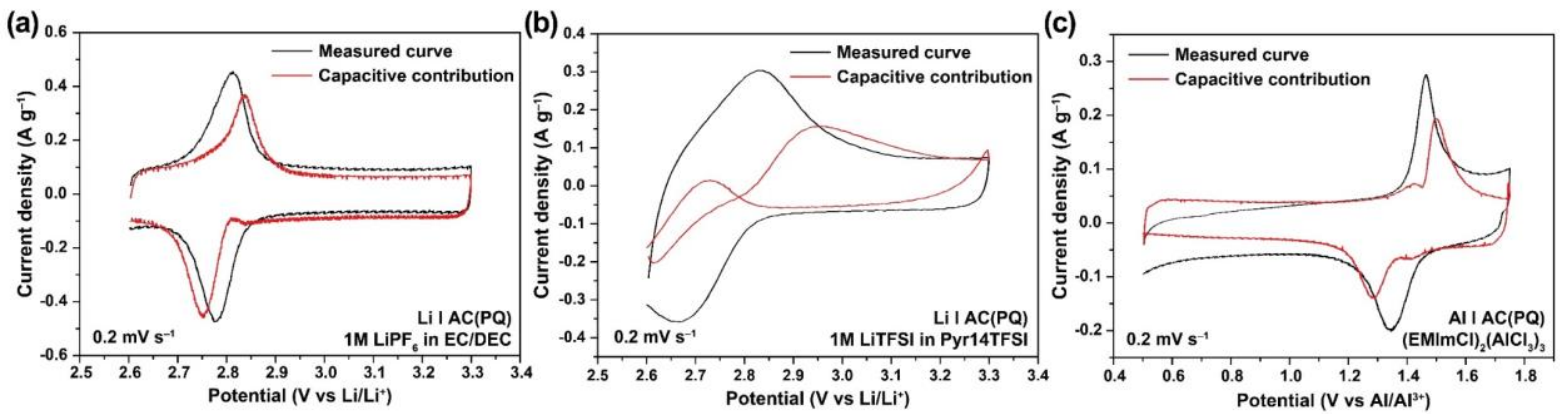

Figure S16. CV profiles along with calculated capacitive contributions (red): (a) 1M LiPF6 in EC/DEC. (b) 1M LiTFSI in Pyr14TFSI. (c) (EMImCl)2 $2\left(\mathrm{AlCl}_{3}\right)_{3}$. 

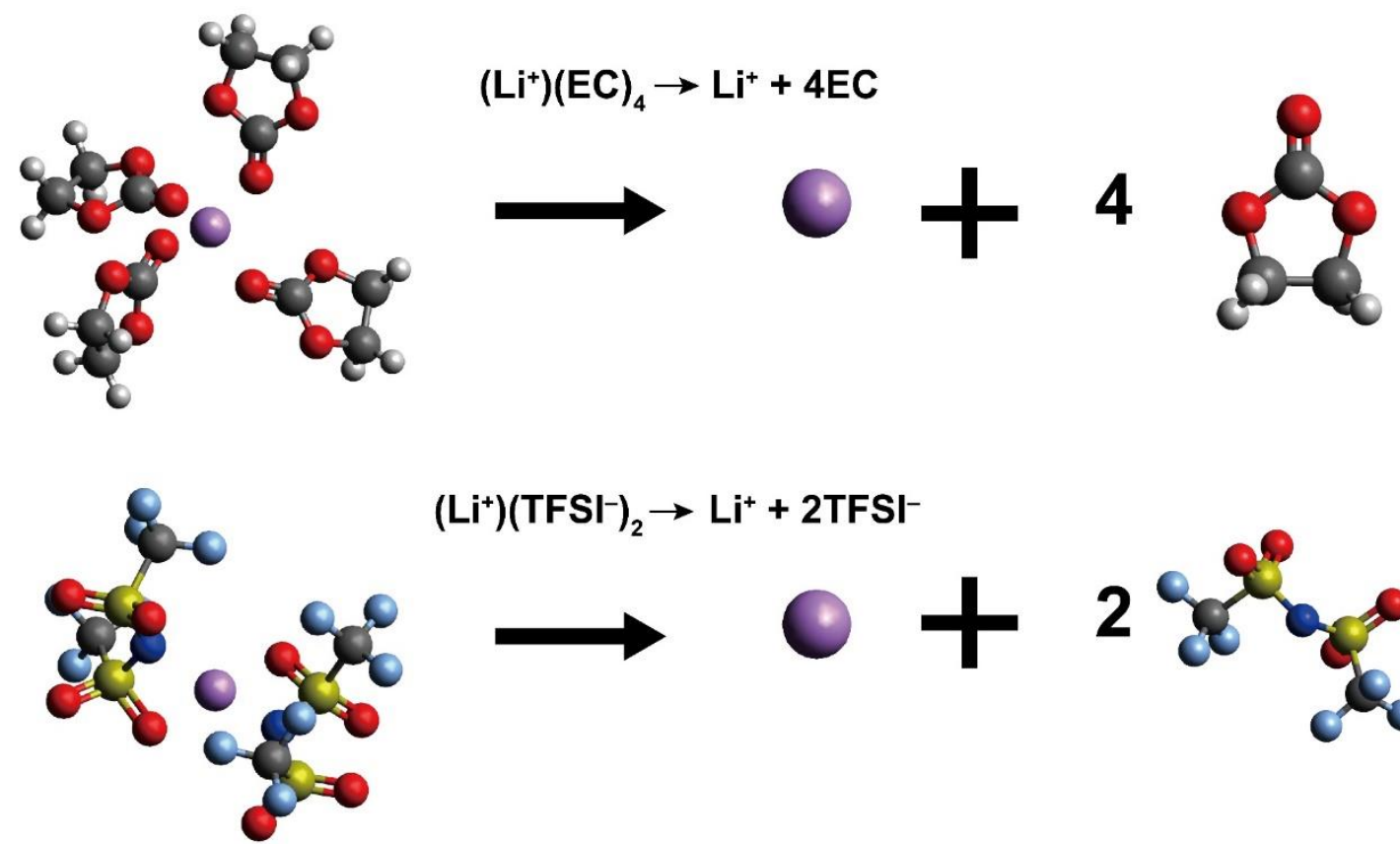

$\left(\mathrm{Li}^{+}\right)\left(\mathrm{TFSI}^{-}\right)_{2} \rightarrow \mathrm{Li}^{+}+2 \mathrm{TFSI}^{-}$

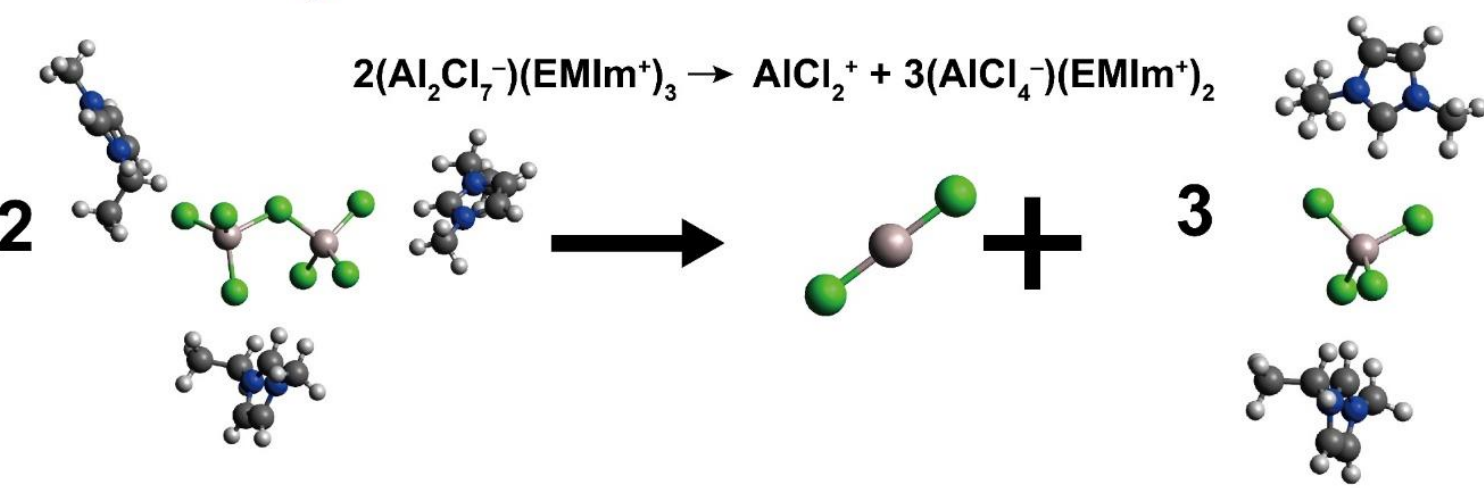

Figure S17. Illustration of desolvation energy calculations in Figure 4c. 

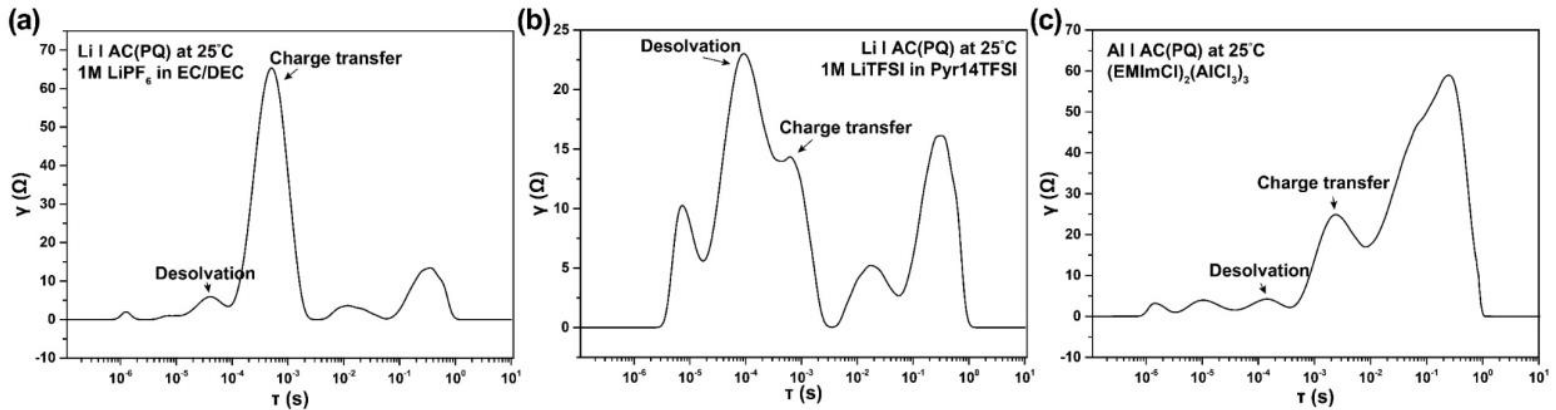

Figure S18. Distribution of relaxation time (DRT) profiles of $\mathrm{AC}(\mathrm{PQ})$ at $25^{\circ} \mathrm{C}$ with (a) $1 \mathrm{M}$

$\mathrm{LiPF}_{6}$ in EC/DEC, (b) 1M LiTFSI in Pyr14TFSI, and (c) $(\mathrm{EMImCl})_{2}\left(\mathrm{AlCl}_{3}\right)_{3}$. 


\section{References}

(1) Kohn, W.; Sham, L. J., Self-Consistent Equations Including Exchange and Correlation Effects. Phy. Rev. 1965, 140, A1133-A1138.

(2) Fan, X.; Chen, L.; Borodin, O.; Ji, X.; Chen, J.; Hou, S.; Deng, T.; Zheng, J.; Yang, C.; Liou, S.-C.; Amine, K.; Xu, K.; Wang, C., Non-flammable electrolyte enables Limetal batteries with aggressive cathode chemistries. Nat. Nanotechnol. 2018, 13, 715722. 